\title{
Exploring (un)sustainable growth of digital technologies in the home
}

\author{
Oliver Bates*, Carolynne Lord*, Bran Knowles*, Adrian Friday*, Adrian Clear ${ }^{\dagger}$, Mike Hazas* \\ * School of Computing and Communications \\ Lancaster University, UK \\ \{o.bates, c.lord, b.knowles, a.friday, m.hazas\}@lancaster.ac.uk \\ $\dagger$ Open Lab, School of Computing Science \\ Newcastle University, UK \\ adrian.clear@newcastle.ac.uk
}

\begin{abstract}
HCI and Ubicomp research often centres around the support of humans interacting with digital technology. Despite this obvious focus, there seems to be less work on understanding how these digital technologies can lead to growth in use, dependence, and influence practices in everyday life. In this paper we discuss how digital technologies have been, and continue to be, adopted in domestic practices-and how the growth of interactions with various ecologies of digital technologies can lead to growth in use and energy consumption. We further the discussion within ICT4S and sustainable HCI on how to promote research that encourages sustainability as a core concern-socially, economically, and ecologically-emphasising that defining limits to growth are important when trying to affect change in sustainable directions. We echo calls for more significant sustainability research from HCI, and set out some avenues of design for moving in this direction.
\end{abstract}

\section{INTRODUCTION}

In this paper, we concern ourselves with a number of interconnected domains that have a long history at the heart of HCI, Ubicomp and more recently ICT4S, research and design. Broadly, we refer to this as 'digital technologies'; under this umbrella falls a whole array of interactive devices like smartphones, PCs and games consoles that support our daily entertainment, work, and communication practices, to mention a few. Our particular focus relates to growth in the social and environmental impacts that the adoption and integration of digital technologies has culminated in.

Digital devices in the home are on the rise ${ }^{1}$, with ownership of wearable technology alone set to double in the next year ${ }^{2}$. Significant rises in energy demand, data demand [1], and GhG emissions follow from this, and some have reported on the potential negative effects of this proliferation of digital technology on domestic life (e.g. "together aloneness" [2]).

This growth in energy and data demand motivates the need to understand the situations in which digital technologies are a) being domesticated into practices, and b) where energy/data demand is intensifying through use in practice(s). Through expanding how we discuss growth it may be possible to

\footnotetext{
${ }^{1}$ http://www.pewresearch.org/data-trend/media-and-technology/ device-ownership/

${ }^{2} 2014$ State of the Internet of Things Study, via http://channelnomics.com/ 2014/09/19/survey-wearable-tech-home-iot-devices-set-rise
}

gain a more nuanced understanding of the environmental (e.g. energy and emissions) and social impacts (e.g. social practices, pressures and expectations) that are effected by digital technologies.

As Pargman et al. highlight, technology (in sustainable HCI) is designed to reduce impacts [3] . Typically this work ignores "a system's inputs and outputs and its systemic effects", contributing to unsustainability by "selectively draw[ing] a tight boundary around the implemented system in question" and selectively measuring their effects [3, p. 643]. Complementing this critique our work aims to provide better understandings outside the boundaries of traditional enquiries (e.g. just focusing on domestic electricity consumption) into the impacts of digital technology by studying how everyday life is affected (e.g. temporally and spatially [4], second order and rebound effects [5]) by a growing reliance on digital technology.

The design of domestic digital technologies influences how technologies are used or not used (becoming obsolete, abandoned or thrown away), affecting social norms and expectations of (and reliance upon) possession and use, which impacts end-use and production demand. In this paper we analyse digital technologies in everyday life to uncover growths in: ownership and usage of devices in everyday life; the extent that digital technologies are incorporated in social practices (e.g. using Shove's reductive social practice model [6]); growth that is encouraged by particular types of users (e.g. connoisseurs [7]); and, the growth in the physical space that practices can be performed [4]. These factors contribute to the escalating (energy and data) demand and growing embodied emissions.

This paper aims to contribute towards improved understandings of technological growth by: 1) identifying useful interpretations and valuations of "growth" as related to digital technologies in the home; 2) providing an understanding of how digital technologies have lead to growth (with this specific set of participants); and 3) pointing to current factors that spur or limit growth in technological usage with an eye to identifying elements or strategies that steer growth in favourable directions. 


\begin{tabular}{|c|c|c|c|}
\hline Name & Living Arrangements & Important & Less Important \\
\hline Bettina & 3 bedroom, single occupant & iPhone, $\{\mathrm{TV}, \mathrm{PVR}\}$ & DVD Player, 3 x PVRs, iPod, CDs, DVDs \\
\hline John & 2 bedroom flat, lives with fiance & $\{$ Smart TV, PS4 $\}$, iPhone & $\begin{array}{l}\text { DVDs, }\{: \text { PS } 3\}, \text { Airplay speakers, } 2 \text { iPads, }\{\text { PC, } \\
\text { monitor, speakers }\} \text {, Macbook, Laptop }\end{array}$ \\
\hline Sarah & $\begin{array}{l}3 \text { bedroom, lives with } \\
\text { partner }\end{array}$ & iPhone, kindle, Macbook & $\begin{array}{l}\text { PC, server, }\{\mathrm{TV}, \text { media centre }\} \text { \{speakers, am- } \\
\text { plifier, Logitech Wireless Music System }\}\end{array}$ \\
\hline Derek & 2 bedroom flat, lives with partner & iMac, iPhone & $\begin{array}{l}\text { iPad, work iPad, TV, Macbook, Speak- } \\
\text { ers, DSLR }\end{array}$ \\
\hline Xander & $\begin{array}{l}3 \text { bedroom cottage, in the country, lives } \\
\text { with Willow }\end{array}$ & $\begin{array}{l}\text { Macbook, iPhone, router, cellular } \\
\text { booster, DSLR, GoPro }\end{array}$ & $\begin{array}{l}\text { tablet, speakers, house iPod, \{Desktop, Speak- } \\
\text { ers, Screen, amplifier }\} \text {, kobo eReader }\end{array}$ \\
\hline Willow & $\begin{array}{l}3 \text { bedroom cottage, in the country, lives } \\
\text { with Xander }\end{array}$ & $\begin{array}{l}\text { Macbook, smart phone, external HDD, } \\
\text { router, cellular booster }\end{array}$ & kindle, DSLR \\
\hline Jayne & 3 bedroom house, lives with parents & $\begin{array}{l}\text { iPhone, }\{\mathrm{TV}, \mathrm{Sky}+\} \\
\text { Macbook }\end{array}$ & $\begin{array}{l}2 \text { x TV, iPod, Printer, Mother's laptop, DAB } \\
\text { Radio, Karaoke/DVD player }\end{array}$ \\
\hline Malcolm & $\begin{array}{l}3 \text { bedroom house, lives with } \\
\text { wife, child and lodger }\end{array}$ & $\begin{array}{l}\text { Smart Phone, Router, Laptop, } 2 \mathrm{x} \\
\text { Tablet, }\{\mathrm{TV}, \mathrm{BT} \text { vision box }\}\end{array}$ & $\begin{array}{l}\text { Wii, DVDs, Sky+ box, Software DVDs, iPod + } \\
\text { dock, mp3 player, memory stick }\end{array}$ \\
\hline Glenda & $\begin{array}{l}\text { Co-housing occupant, lives half a year } \\
\text { in France }\end{array}$ & $\begin{array}{l}\text { iPad mini, Macbook, } 2 \text { x iPhone, iMac, } \\
\text { Time Machine, TV, } 2 \text { x DAB radios, } \\
\text { high end HiFi, Landline, DSLR }\end{array}$ & 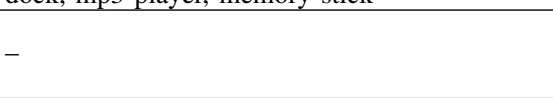 \\
\hline Ron & $\begin{array}{l}2 \text { bedroom bungalow, lives with } 2 \text { of his } \\
\text { grandparents }\end{array}$ & iPhone, Macbook & $\begin{array}{l}\text { Vinyl records, DVDs, Blu ray, TV, PS3, } \\
\text { DVD/VCR, Sky+, camera, stereo separates (CD, } \\
\text { Cassette, Record, Amplifier }\end{array}$ \\
\hline
\end{tabular}

THE INVENTORIES OF OUR PARTICIPANTS, DIVIDED BY WHAT THEY CONSIDERED IMPORTANT AND LESS IMPORTANT. CONSTELLATIONS OF DEVICES ARE GROUPED IN BRACES, AFTER BATES ET AL. [7].

\section{RELATED WORK}

'Sustainable HCI' often concerns itself with reducing the energy or environmental impacts associated with daily life. We propose a different tack: we instead critically reflect on the impacts of hardware, software and services that our participants use, and how they contribute to designing, implementing and implicitly promoting unsustainable practices and trends.

Perhaps closest in both method and motivation are studies which have used personal inventories and domestic objects as a basis for exploring the role of physical and virtual 'stuff' in everyday practice. Such studies have included: insights into how home network technologies could support better user management [8]; understandings of the short lifetimes of mobile phones [9]; frameworks of personal attachment to inform the design of devices that are longer-lived and more likely to be cherished or passed on to others [10], [11]; reasons why electronic devices are kept even after they have fallen out of use [12]; how meaning is composed for digital data (messages, photo, video) compared to physical possessions [13]; how we might better support those who already devote significant effort and resources to reducing the impacts of their lives at home [14]; and how purchase, reuse and disposal of personal digital technology may relate to environmental concerns among young people [15].

Unlike the above works, we chose not to zoom in on any one element-such as specific devices like the mobile phone [9], [16], addressing obsolescence of end-user devices [17] or the specific reasons for acquiring new technology versus re-using old [10], [15].

Whilst digital technology in everyday practice has been looked at before (e.g. [18]), very little of this work has done so from a sustainability angle. Our approach is similar to that of Håkansson \& Sengers' "simple living households" [19] and Kawsar \& Brush's [20] study with a more conventional group, investigating the configuration of computer activities across devices, and the temporal and spatial arrangements of device use and computer activities in the home. Likewise, we take a broad view of our participants, looking at their whole 'ecologies' of devices (e.g. "implicit or explicit relationship among interactive artifacts in one's personal life" [21]), content and services, along with the varied daily practices in which these are implicated. As a result-and in contrast to Kawsar \& Brush - we use a sustainability lens to provide a stark illustration of how current configurations of digital technologies are as much about a) the day-to-day practicalities of employment and education, collaborating with others, and caring for loved ones, and b) about the happenstance of borrowed tech, handme-downs and contact with people having certain kinds of IT expertise, as they are about personal attitudes and meanings associated with specific devices or items of digital media.

\section{METHODS}

To understand the growth and use of ecologies of digital technology in the home relate to, and support everyday life, we conducted a qualitative study of 10 participants (seen in Table I). The participants were recruited using flyers, newsletter advertisements and direct email between March and August, 2014. Each participant was assigned a pseudonym.

Our study was designed as an extension of the Personal Inventories method [10], which was further refined by Gegenbauer et al. [12], where home tours were replaced with an autoethnographic 'photo-elicitation' process. The study consisted of two-phases: 1) a photo elicitation (of digital technologies) exercise, where participants were loosely instructed to photograph anything that they considered to be "media or IT" and a part of their "daily life"; and 2) a follow-up interview that lasted between 60-100 minutes conducted away from the home. From their inventories the participants were asked to identify a primary device if they had one, along with which technologies they felt were important and less 
important in their everyday lives (see Table I). The photographs captured by participants were hand-annotated by the researchers, and then used to construct an interview schedule customised around those technologies deemed important by the participant.

To understand the coupling of device use within practices in the home we designed our interview questions and analysis around the reductive model defined by Shove et al. [6, ch. 2], focusing on all three elements: material (e.g. the devices owned), meaning (e.g. what the practice means to the person, and how this is affected by the material element), and competencies (e.g. how complex their practices are, the skills and know how associated with the practice).

The participants' descriptions of the domestication ${ }^{3}$ and use of their digital technologies, captured in the interviews, revealed trends of growth in terms of ownership, use, reliance, and the spaces that technology has become used in. Using these trends, 2 researchers independently coded the interview data and then agreed on six overarching themes of growth. We now explore what we mean by growth (section IV) and how each of these themes contributes to growth (section V).

\section{EXPANDING THE UNDERSTANDING OF GROWTH}

The term 'growth' when used in an ICT4S context is usually linked to the 'directionality' of the growth in ICT and digital technologies (e.g. growing emissions and impacts, growing ownership of digital technologies) but is there more to say? To better understand growth it is important to consider the social implications of technologies (e.g. adoption in practice, dependency upon it).

While this study only reflects a snapshot of a fairly restrictive set of participants' digital technology-our participants could be considered typical middle class, first world citizens, at different periods of their lives and careers-we can also clearly see an ostensibly typical variation of ownership, configuration and importance attached to the kinds of technologies interwoven in their lives. The more and less impactful performances and the associated trajectories of practices they enact in turn lead to different energy and emissions impacts [23].

Growth in reliance on digital technology has been observed to have negative first-order effects on the environmental impacts (e.g. arising from manufacture and distribution), but can lead to reduced second-order effects (dematerialisation of various practices, telecommuting) [4]. These reductions may be counteracted by third-order effects in specific practices (e.g. maintaining digital friendships that transfer to more frequent digital and non-digital interactions), leading to increased total energy consumption [4], [24].

Reliance on digital technology has grown and become more engrained in everyday life. To better inform more 'holistic' understandings it is important to consider both: how demand is growing due to the co-evolution of digital technologies and social practices; and, where growth in digital technology is

\footnotetext{
${ }^{3}$ An approach within the social sciences, first introduced by Silverstone et al. [22], to describe the processes by which a new technology is 'tamed' by its users
}

occurring outside of energy demand. For example, streaming video may be lower impact than buying physical media, but the video-on-demand service creates more repeat opportunities for demand and growth (i.e. across devices, locations, simultaneous shared access). The co-evolution of technology and social practice can manifest in different ways. By studying how digital technologies are domesticated and are situated 'inuse' in everyday life it is possible to gain new insight into the link between third-order effects and the growths that can be observed in social practices.

\section{EXPLORING GROWTH}

In this section we explore the relationship between growth and our participants' social practices. We discuss the following categories of growth: 1) single devices; 2) sets of devices; 3 ) individual practices; 4) groups of practices; 5) single and sets of users; and, 6) the spatiality of practices. Sets are used to describe where growth has been affected across multiple (physically or virtually) connected entities. These categories of growth are connected to sustainability through their impact on second and third order effects [4], [24].

\section{A. Growth in single devices}

The number of new mobile applications available is increasing monthly ${ }^{4}$, expanding the pool of potential uses of mobile devices. All of our participants owned smart phones, and seven of them have access to at least one tablet computer.

Derek, and Malcolm both found that their tablets are central to work and leisure. Derek, uses his tablet throughout the day to support work (e.g. email, notes in meetings, appointments) and in his free time for catching up on TV (on-demand and catch up TV). Malcolm uses his tablet throughout the day for work, and in the evening for keeping up with current events, browsing and emailing.

Bettina's increasing use of her smart phone stems from not having a conventional land line or home broadband. She is dependant on her iPhone and sees it as "her lifeline" as it was her "alarm clock, [...] only access to the internet, it's my diary, it's got my music-it's everything. So if I didn't have my phone I'd be in trouble".

These examples show how relatively new digital technologies are growing through their incorporation in practices that used to be performed on other devices (i.e. browsing and email used to be associated with desktop computers).

\section{B. Growth in sets of devices (e.g. ecologies and ecosystems)}

Ecologies of related digital technologies grow through the addition of new technologies. For the new technology to be integrated in everyday they pass through two phases, adoption and integration [25]. The ownership of one technology from a single manufacturer can sometimes lead to future purchases from the same manufacturer, leading to growing ecologies of a particular ecosystem (e.g. Ron and Glenda's reliance on Apple

\footnotetext{
${ }^{4}$ Birth, life and death of an app. A look at the Apple App Store in July 2014. Adjust 2014 (https://www.adjust.com/assets/downloads/ AppleAppStore_Report2014.pdf)
} 
products). Interlinking of devices (constellations or groups of devices that are used together) exist within ecologies of digital technologies, and often are integrated into a subset of a users' practices. Constellations are often networked ecologies that enable expansions of practice through connected or networked peripherals (e.g. a Chromecast connected to a TV enables a wider set of practices which now include the $T V$ in the constellation to enable the performance) [7].

John's purchasing of a smart TV led to his old TV being moved to the bedroom. Re-adoption (or re-domestication) of technology, and re-definition of the meanings of technologies [25] (e.g. John's old TV now having a different meaning in his ecology) play a role in the growth of digital technologies, as technologies that have already been adopted and integrated into practice can more easily_as we see for John's second TV-be re-domesticated.

Ron regularly upgrades to new technology. He currently relies on Apple products: a new MacBook pro and iPhone 5s. The importance of the features of this ecosystem are clear as Ron values synchronous content, communications (twitter, email and instant messaging) and cloud applications (e.g. iCloud, iTunes Match) as they enhance his workflow and everyday life. Ron tries out and chooses cloud based services and applications that enhance his practices, enabling him to perform them when and wherever he requires.

\section{Growth in individual practices}

Growth in practice occurs when elements of the practice are highly valued or develop a competence or meaning that also rely on digital technology. For example, with John's purchase of his new smart TV and PS4, the importance (meaning) of the gaming had increased as he had invested in a new technology and higher quality of experience, leading to increased frequency of use of this constellation. Similarly, Jayne's latest smart phone enabled her to follow tennis whilst she was away from the her home TV. Jayne is passionate about tennis, so this lead to her using the official Wimbledon app and updates via Google on her phone to access fixtures and scores throughout the day.

Communication is increasingly facilitated through a growing number of applications, leading to growth in frequency of use. Malcolm uses 'Line' - an alternative to texting that uses to data connectivity instead of cellular-due to poor cellular network coverage at his home. Instead of going without, Malcolm (and his wife) substituted the materials of their communication practices to include a new application, allowing them to maintain a constant stream of communication. Willow also uses Line to maintain more regular contact with a friend currently working in Japan. Jayne uses iMessage on her iPhone to maintain group conversations between 4 close friends. Facebook was used by several participants to communicate with friends (Xander, Sarah, Willow, Malcolm). Facebook allowed for participants to switch between devices (e.g. smart phone to laptop), and enabled communication to incorporate the sharing of links to video and photos between the group. Our investigation revealed that communication with friends and family is a high priority for all of our participants and as a consequence, the expectations surrounding these practices have grown (e.g. faster response time to messages, ability to share photos, group messaging, international conversations); further contributing to the growth in their practices and their impacts.

\section{Growth in sets of practices}

Through multi-functional digital technologies (e.g. laptops, smart phones, tablets), and growing ecologies of digital technologies, the sets of practices that can overlap, or be performed at the same time, become larger and more complex (e.g. listening to music whilst cooking, emailing or working whilst watching TV, media and backup servers running in the background, normally continuously).

Glenda owns primarily Apple branded digital technologies and recently completed Apple training. Motivated by her training, she is now more competent in using her Apple ecology leading her to use digital technologies more frequently in larger sets of practices (e.g. communication, work, leisure).

Background tasks such as automated backing up, and streaming media (either locally or from the Internet) are often done in the background of other practices whilst the devices are active and connected to the home network. Xander and Willow rely on their media server "pancake" 5 for accessing their joint media library and for regular, automated backing up. Ron, like Xander and Willow, automatically backs up his data. Using both iCloud (for his phone) and a backup service BackBlaze $^{6}$ to host all of his data and media in the cloud.

Sometimes digital technologies play a part in sets of practices that don't always contain digital technology (e.g. Jayne, Xander, John, Willow stream media whilst they cook). For Malcolm, the iPad paid a crucial part in maintaining his son's attention whilst trying to get him to eat, "He doesn't like to sit still, and so to get some food into him what we do is get the tablet on the dining room table and we'll let him use Youtube[... IIf I had nothing else, I'd need my sons tablet, otherwise he'd starve.".

\section{E. Single users and sets of users}

Higher levels of growth can be attributed to individuals (connoisseurs) who "strive for a high quality of service or experience" [7, p. 1178]. Due to higher competence with the technology, connoisseurs typically optimise their practices toward performances that include more digital technology and larger constellations, with more and more frequent upgrades [7].

The effects of connoisseurship in the home has knockon effects for others who share technology and space (e.g. Xander's configurations lead to his partner Willow's practices having higher impact). Sarah could be seen to share her housemates' technologies. Whilst Sarah had many photos to

\footnotetext{
${ }^{5}$ Pancake is an old laptop that has a broken screen. It is used as network attached storage (NAS), with $2 \times 2$ TB external drives, one for back ups and media content, the other for redundancy of the media and back ups.

${ }^{6}$ https://www.backblaze.com/
} 
discuss in her interview, the only devices that were solely hers were her iPhone and Kindle. The others were shared and required a negotiation of sorts given that "everything in the house is custom built" by her housemate.

There were definite benefits, however, and Sarah described how she uses her housemate's MacBook on a daily basis when home, as her own had broken. Her own remained in the same state given that,

... "No it's fine because there are several laptops in the house, [...] everyone else is ok with me using one of their spares, or their main laptop. That's fine"...

Sarah's housemate, like several of our participants (John, Xander, Ron, and to a lesser extent Malcolm) is a connoisseur who has custom built the constellations and networks in the home used by Sarah. John and Xander both own and maintain custom constellations of digital technologies to heighten their experience. Ron has a specialist collection of vinyl records, and has optimised his work flow between his iPhone and Macbook, communication and leisure experiences through the use of a variety of customised Internet and cloud applications. Malcolm's fondness of gadgets and technologies lead him to incorporate technology throughout his life "I like gadgets and I've always tried to become as tech'd up as possible".

For Jayne, the access to technologies owned by her parents lead to her having a higher impact. The configuration of the digital technologies in her home are the responsibility of her parents: they provide multiple TVs, and have configured the home network. Jayne is aware that the configuration of digital technologies, and observes that her father's practice of using the computer in a warmer room to access files from a desktop computer in the cold study is inefficient, but feels that it's not her place to suggest improvements to 'his' configuration.

\section{F. The spatiality of practices}

The spaces in which practices can be performed are growing, both within the home and outside of the home. Growth in the spatiality of use occurs for three reasons: 1) mobile technologies (e.g. laptops, smart phones, tablets, e-readers) are not restricted in space like other digital technology (e.g. TVs), 2) the spread of network connectivity allowing access to Internet and cloud services (e.g. on-demand video, email, browsing) in more locations, and 3) technologies provided by an employer or bought for study also have use beyond their intended purpose, and end up being integrated into more domestic practices.

Some, such as Malcolm, could be seen to value the access that their mobile devices gave them to work resources. This allowed them to work away from their workplace, although this did appear to influence their perceptions of appropriate activities at work. This was summarised by Derek who explained that: "If I look at some personal emails at work that's fine because I do work emails at home."

When talking about their digital technologies, Derek, John, Xander all identified technologies in their possession which had been bought for them by their employer. This meant that duplicate technologies were often owned (e.g. Derek had two
iPads, John's work iPad was used as well as his finacée's). Despite this, the uses of these work devices were frequently seen to blur the boundaries of work, and bleed into practices of leisure and domesticity.

Similarly to growing social pressures (e.g. Jayne choosing an iPhone so she can communicate with her friends via iMessage), work provisioned technology can be seen to expand practices through practitioners finding ways to integrate new technologies into other practices (e.g. Derek using his work iPad for watching on-demand video, John using the work iPad to cast content to his Chromecast connected to his TV).

Having carried out much of her preparation work on her laptop, Willow was now finding it difficult to make the distinction between work and home life, impacting on her productivity. Certain consequences of this on participants' experiences were clear. Willow, for example, found that she frequently worked on her laptop when she'd previously intended to carry out more leisurely activities.

"I haven't found the work-life balance yet so it's kind of being more working. I think it could be a reason for switching to the tablet, not that I have, but there's so much work stuff on there that even if you are sitting there, and you are browsing the Internet, or doing something else, I'll have the Powerpoint window up there [... ]"-Willow

Despite the way in which technologies have been cited for increasing flexibility and improving productivity in (and out) of the workplace, the effects can be seen to carry on beyond the working day; increasing both negative (e.g. squeezing of time, leading to 'harridness' [26]) and positive influences (e.g. flexibility) over the way that people perceive the divide between their work and home lives.

\section{CAN WE REDRESS GROWTH IN USE HEAD-ON?}

Growth linked to digital technologies has featured in the everyday lives of our participants. In this section we reflect on the difficulties that are faced when trying to redress the previously outlined growth.

\section{A. Felt importance}

From the interviews, it was clear that certain practices were more important to the participant as they negotiated (with themselves) over which digital technology was more important than another, and why. Often, communication with family and friends was the practice held the most highly, spanning multiple devices, and leading to their important device(s) being linking tightly to practices of communication.

Glenda's digital technologies were especially important to her whilst she was in France, as they were only means of communication to family, friends and for work. Her communication was enabled across multiple technologies in her ecology (e.g. iPhone, iPad, MacBook), and spanned space due to her having to find Wifi spots outside of home. Malcolm's choices of important technologies revolved around maintaining contact with his family, and ensuring their comfort. Malcolm felt that the TV and connected peripherals (its constellation) are 
important for his wife's well being, and sanity. Having been re-appropriated, the iPad was seen to be absolutely essential as it was linked tightly with keeping his son occupied enough at meal times to ensure that he ate.

For all the participants, the breakage of an 'important' technology (see Table I), would result in immediate replacement of the technology (usually within a couple of days), even if they had another device which was capable of performing the same function. For example John values his leisure time highly, which mostly revolves around the usage of his smart TV and connected devices (e.g. constellation). His desire for new and up to date technology (e.g. his love of TV and video games) meant that he would replace any important device (e.g. his smart TV, PS4, iPhone) if and when it broke. On the other hand, his laptop is provided by work, and is subsequently seen as less important, and something that would be replaced by his employer.

With this in mind, how can researchers consider what is negotiable in terms of technology? In understanding what people are doing with their technology, and the meanings associated to this it becomes obvious that simply telling people to reduce their use will not work.

\section{B. Dependence}

Dependence on Internet connectivity was displayed across all the participants. From the photos, the majority of participants' device ecologies relied upon Internet connectivity. The participants indicated a high dependence on digital technologies that were used for communication (e.g. smart phones, laptops, tablets) and home network infrastructure (e.g. routers, cellular boosters). These devices were seen as an integral to our participants' lives. For Xander and Willow, dependence on connectivity was a focal point in the interviews. They had recently moved into the country and were faced with unforeseen communication problems, "[we had] issues where the broadband, I think water got on it, and it was just cutting out every three minutes and we were going crazy. You were just cut off." -Xander.

Through the interviews, eight of the participants revealed that particular digital technology allowed them to work whilst at home or on-the-go (e.g. John, Glenda, Xander, Willow, Malcolm). Ron's dependence went beyond this, stemming from his Apple ecosystem (e.g. MacBook, iPhone) and reliance on paid for services (e.g. iTunes Match, iCloud), along with functionality he found essential for his DIY concert organisation (e.g. email, Adobe Creative Suite for creating promotional materials). Jayne discussed buying an iPhone to allow her to talk to a selected group of her friends via iMessages group messaging.

We can also see how the expectations of others (e.g. employers, friends) can lead to quicker upgrades, the purchase of particular models or brands, and other behaviours which could be considered to influence unsustainable trends of technology. These pressures strengthen dependencies that lead to the uptake of new technologies (increasing the energy intensity of previously established configurations of practices), which in turn offered newer or additional features, that then led to expansion of existing practices further throughout their daily lives.

How do we negotiate dependence on technology in practices? Perhaps we need to look at making interactions harder, or less convenient to break away from dependence?

\section{Competence}

The complexity of the digital technology configurations varied between participants, due to the their knowledge and passion for their domestic digital configurations (e.g. home networks, connected devices). Higher levels of competence was seen to increase the complexity of constellations in the home, leading to more impactful configurations (e.g. larger connected ecologies and constellations, more frequent use of digital technologies in practice) through connoisseurship (e.g. Xander, John), or having access to digital technology configured by a connoisseur (e.g. Sarah, Willow). Alternatively, lower competence can encourage people to be easily swayed by friends and families (e.g. influence from others, lead to using wasteful configurations of technology (e.g. Jayne), and lead to relying on more impactful ecosystems (e.g. Apple) with short lifecycles (e.g. Ron, Glenda).

Higher competence, often from connoisseurship, leads to larger and more complex constellations being used (John, Xander), as well as more reliance on cloud based services (Ron) and larger investments in data (Xander). With this in mind it is interesting to consider how competence plays a part of growth in device use and social practices. Bates et al. suggest that connoisseurs are potentially the most likely to respond in a make more sustainable choices when trying to lower the energy and emissions associated with media and IT [7]. Our findings point to the contrary. Through our study they showed that dependence on technology (Ron), convenience and financial comfort (John), and prioritisation of family needs over greener digital technology (Malcolm) ${ }^{7}$ are all factors that can prevent connoisseurs from considering more sustainable trajectories (e.g. slower growth) for digital technologies.

\section{REFLECTING ON GROWTH}

Although we are able to categorise areas of growth, and potential barriers, we found that the participants were faced with circumstances that had been out of their control. These circumstances make it more difficult to redress growth in domestic digital technologies head on. In this section we highlight circumstances that effect digital technology use in our participant's daily lives.

Hand me downs and gifts. Derek discussed the way in which he had received his TV on account of family members updating their own, and having passed on their old model to him.

... "It was like, there's a spare TV in the family-Derek's moving into a house-here you go, have a TV. To be honest

\footnotetext{
${ }^{7}$ Malcolm was put off buying a Fairphone (http://www.fairphone.com/) due to the additional costs compared to buying a phone off of eBay.
} 
if we hadn't been given that, it's unlikely that I would have bought one. 'Cause I already had an iPad"...

Given Derek's preference for catch-up TV over scheduled broadcasting, he explained its continued presence by saying " $i t$ seems like you have to have a TV in the house don't you?". Removal of the TV, however, would have directly impacted his partner who watched live programs. This meant that it remained in the house, despite the other technologies available to carry out the same practice (two iPads, iMac, Macbook).

Similarly, Xander was left with an unused tablet that he was unable to appropriate. In having received the tablet as a gift, the 'imaginative work' [27] during appropriation was not conducted and Xander found that the device was unable to fit into his ideas of what a tablet should and can be used for, leading him to later acquire a new Kobo e-reader with a better battery life; just for reading. With Xander unable to find a place for the tablet, Willow went on to use it regularly.

It has been suggested that lower impact devices could be a viable alternative for performing similar practices with higher impact devices [7]. Our study shows when an additional device joins an ecology, it doesn't necessarily get chosen for use, and can encourage more use of more devices in daily life.

Negotiating periods of no connectivity. Although Xander and Willow struggled watching their favourite TV shows whilst they were suffering from intermittent Internet connectivity in their house, they negotiated this by maintaining a hoard of content that required longer periods of connectivity than instant messaging (e.g. streaming media, uploading videos and photos for family) and performed pre-loading and uploading when they had more persistent connections at work or in public Wifi areas. Pre-loading of content has been suggested by several researchers for reducing demand at peak times [1], [28]. Xander and Willow's experience shows that while the pre-loading of content is inconvenient and requires additional effort, it still allows them to enjoy watching TV.

One connected device is enough. Bettina, who lived alone, demonstrated the way in which her particular circumstance (in this case financial) affected the uses of digital technology. The frequency of use of her laptop had fallen since she stopped have an Internet connection at home. Regardless, she appeared to negotiate not having an Internet connection at home effectively, and was able to carry out those tasks that she required from it at work or with her iPhone. When asked whether she'd consider installing a connection were money not an issue, she replied:

... "Absolutely. But because I'd have to buy the phone line and then you know, the monthly payments for that, and then the monthly payments for the Internet. It's just way over my budget. So, something has got to give... and I'd rather eat [laughs]"...

This points to some digital technologies having the potential to be seen as more negotiable, with a smaller ecology of devices being a viable alternative if circumstances change.

With this all in mind there are opportunities to dissuade or slow growth. Although barriers such as felt importance can encourage stronger relationships with digital technology, lead- ing to dependence, these strong relationships can be shaken up in the occurrence of circumstances that affect wider practices (e.g. Xander and Willow's Internet connectivity disruption, Bettina's financial constraints). Our participants willingness to change their practices around inconvenience shows that it may be possible to influence slower growth of digital technology and everyday life.

\section{TOWARDS LIMITS TO GROWTH: DIRECTIONS FOR ICT AND SUSTAINABILITY}

Taking into account what we have learned from our participants, this section lays out some initial directions for designing digital technologies in ways that are more congruent with sustainability and more cognisant of the ripple effects of such designs. In line our with recent calls for more radical research questions we present a set of design ideas and directions that are fitting when considering how to limit how digital technologies are growing into our lives. (c.f. [29]) that might lead to higher impact wins for sustainability. We end with questions our study has raised and new challenge areas it highlights, not to provide answers or solutions ourselves, but to inspire discussion within the community and amongst practitioners who may not (yet) consider sustainability in their work.

Historically, research in computing that concerns sustainability has lead to suggestions for affecting small scale 'sustainability' impacts. They reflect (and are meant to reflect) a particular, historically pervasive framing of the sustainability problem, whereby minor adjustments to the way we live and the way we design for living will suffice for meeting sustainability requirements-a reformist stance, as opposed to radical stance [29]. Traditionally, such framing fails to account for the true scale of the sustainability problems we face (e.g. climate change), and fails to acknowledge their 'multi-scalar complexities' [30], and hence leads to overestimations of the value of these kinds of contributions. We fully acknowledge - and hope others recognise- the limited nature of the impact that the avenues for future work we propose might have, even in aggregate and combined with everything else we are doing as a community. In terms of energy alone, when we think in terms of a focal point that ostensibly motivates energy reduction efforts, such as arresting climate change, the phrase 'a drop in the ocean' comes to mind. Furthermore, these kinds of interventions do not appear to address underlying causes that give rise to current design trends regarding the development of digital technologies and the practices surrounding their use, and in so failing, would seem to reinforce the precarious view that sustainability can be achieved without the need for significant changes to our comfortable, high-tech, and media-filled lives.

The sustainability framing we are critical of tends to go hand-in-hand with assuming the flexibility of so-called limits. The more radical stance we advocate in this paper, again in alignment with recent Collapse Informatics publications (c.f. [31]), is that there are finite limits to growth [3]. In this case, throughout this paper we operate under the assumption 
that there are limits to the amount of growth in technological usage within which we might achieve 'sustainability'.

\section{A. Attending to growth of on-demand media from background tasks}

Early on in Sustainable HCI [32], a distinction was drawn between 'sustainability in design', which explores how to reduce the impact of the technology itself, and 'sustainability through design', looking into ways that technology could developed to impact on other areas of sustainability concern. To address the growth trends of streaming on-demand background media through it maybe appropriate to apply 'in design' angle. We note here the ways that background tasks (e.g. cloud or local back ups, and streaming of media) layer on top, or underneath of other sets of practices of our participants, and that this leads to additional layers of energy (data, etc) demand. With the growth in on-demand media, especially in during peak demand hours ${ }^{8}$ we suggest that designers should adopt a sensibility whereby 'background' streaming of certain content is 'wasteful' - similar to people now knowing not to leave lights on when they leave a room. Drawing inspiration from strategies suggested by Preist and Shabajee [28], 'wasteful' demand could be targeted to reduce digital waste. This could be an opportunity to re-evaluate caching on local devices, prioritising playback of cached media instead of new content (e.g. caching YouTube playlists and iPlayer content for Malcolm and his son), alongside time shifting the downloading of new content to not coincide with peak (energy, data) demand. For a slightly higher impact solution designers could disrupt temporal expectations of streamed media by purposefully creating latency on high quality and large streams to try and encourage low (or no) bandwidth alternatives (e.g. like Xander and Willow's pre-loading).

The growth of background, high-definition content being streamed poses serious implications for network and Internet service demand during peak hours. This is especially relevant when considering how the impacts of streaming media is likely to grow with the roll out of auto-playing video (e.g. YouTube's recent addition of autoplay) alongside 'ultra HD' content and growing screen sizes and resolutions of devices.

\section{B. Integrating, or customising, work and personal profiles on devices}

There is a strong track record of formative user studies within Sustainable HCI research that seek lower impact design solutions that take into account the 'cultural constraints' [33] that circumscribe unsustainable practices and make them difficult to change. In line with this tradition, we note the blurring of boundaries between work life and home life highlighted by six of our participants, resulting in duplicate ownership of devices (e.g. one for work, one for home), and growth in practices (e.g. integrating technology from work in new

${ }^{8}$ Cisco Visual Networking Index: Forecast and Methodology, 20132018http://www.cisco.com/c/en/us/solutions/collateral/service-provider/ ip-ngn-ip-next-generation-network/white_paper_c11-481360.html practices) which has clear sustainability implications in terms of device manufacture, use and disposal.

Working within these constraints, it might be possible that better device harmonisation between work and home would reduce the need for additional hardware. We suggest that more compartmentalised work and home profiles for hardware and software could be designed that prioritise compatibility and security, and allow users to use digital technologies more comfortably in certain settings. Alternatively profiles could be customised in ways similar to internet filters in workplaces or schools (e.g. blocking certain applications or features), encouraging non-incorporation of work provisioned digital technologies. This may lead to less digital technology being adopted and integrated into non-work practices (e.g. both John and Derek have incorporated their work tablets into their domestic practices).

\section{Growth from sharing, gifts and hand downs.}

The argument for sharing technology has been made before in sustainable HCI [34]. In contrast to Blevis [34] and Brush et al. [35], we believe that sharing of non-essential technologies can be worse with respect to sustainability impacts (e.g. connoisseurs like Xander and John sharing their constellations with their partners leading to higher impact practices, Derek's parents gifting him and his partner a TV leading to nonincorporation for Derek and a larger ecology). It is important to consider how sharing can decrease impacts and demand, but we must also be careful to consider how shared devices can serve as gateways to growth in use, practices, and lifestyles (e.g. through the use of complex constellations). There appear to be certain points at which sharing can influence larger demand. Consider that a shared resource (e.g. sharing an Internet connection) may reduce impact, whereas sharing access to a complex constellation of digital technologies can increase demand (e.g. Sarah, or Willow using their respective housemate's constellations). ICT4S, and broader sustainability communities should consider evaluating the demand of sharing digital resources, especially when these resources can lead to higher (i.e. negative) impact and growth in practices.

\section{Designing for non-reliance}

It was surprising to observe with our participants how quickly technologies that did not even exist until recently have become indispensable (e.g. heavy reliance on cloud services, streamed media and mobile devices). Their indispensability does not necessarily comport with reality-for example, life would be liveable without a tablet, no matter how much one may have grown accustomed to it; yet there is a certain degree to which technology has integrated itself into normal practice that means that its breakdown would 'be catastrophic'.

To encourage non-reliance on digital services, and slower growth in device use, compromises on UX (e.g. more caching), or new functionality to enable higher resilience in the occurrence of a failure (e.g. increased offline functionality for less cloud reliance, collapse proofing in the event of infrastructural or societal collapse [31]). Inspiration might be drawn from 
simple-living families [19], whose more offline style of living would likely be minimally disturbed in the event of certain failures (e.g. cloud service failures, problems with streaming).

In addition, and as a corollary to the above - as a means of potentially enabling greater focus on such pursuits-it is worth considering how to reduce people's reliance on non-necessary digital technologies (e.g. technology considered less important). Getting to grips with how to affect these attachments and design for casual usage is not a simple challenge by any means, as it requires anticipation of practices that might arise through use. Nonetheless, the fact that our participants deemed ICT such as smart phones, laptops, e-readers, tablets and TVs (and peripherals) as important, non-negotiable fixtures in their lives is problematic if/when we face serious decisions about what to devote resources to maintain in a collapse future.

Current technologies encourage soft temporal and spatial constraints leading us to be 'switched on' or 'plugged in' more [4], which both extends practices outside of the home and increases energy demand [1]. This can be seen to have both positive and negative implications. For example, to take some of the pressure off, Malcolm's phone allows him to handle his work correspondence whilst baby-sitting or picking his child up from pre-school. It's important to consider how the technologies shape everyday-life in such ways that can lead to 'multiple temporalities', leading to more fragmentation and rushed practices [36]. We wish to reiterate calls to consider design of technology to enable as well as encourage people to maintain a more casual attachment to their technologies. For example, we should consider how to re-design existing technologies to enable people to disconnect and use highly demanding technologies less (e.g. encouraging people to stream less, and even to switch off devices altogether and venture outside). There already exist interventions that remind users to take breaks, for example, but an interesting question to explore is whether and how features inherent in the design of ICT and associated software might support reduced adhesion to screens. How might we anticipate or evaluate whether our research encourages a reliance on technology that we don't (or shouldn't) even need?

\section{ARE THERE LIMITS TO THE GROWTH FACILITATED BY DIGITAL TECHNOLOGIES?}

Amongst our participants we have observed that an abundance of digital technology have enabled and in some cases necessitated more technologically complex and media-rich lifestyles (e.g. growing sets of interconnected devices being used in practice), resulting in continually increasing demand (e.g. Ron and John). And yet, clearly this is a win in economic (and some might say cultural) terms. This points to the issue raised by Silberman et al. [30], namely the tension between (environmental and social) sustainability goals and a need to continually produce new technologies that the public will crave. We echo their suggestion that a sustainability agenda may require a shift in focus from more and more toward repurposing of old technologies to meet new needs. And yet, we recognise that this may not resolve the fundamental tension here, that doing so would appear to be catastrophic for the ICT industry unless some productive harmony can be designed between economic and environmental/social sustainability aims.

\section{A. A low-carbon future for non-negotiable technology}

It is worth considering the broader, global implications of digital technologies becoming 'non-negotiable' (e.g. technology we are highly dependent on). In particular, the nonnegotiable technology owned by citizens of today's Western societies will soon become non-negotiable world-wide. This growth in non-negotiable technology has staggering implications for the relative environmental impact of digital technology. But given that there are technologies we really cannot fathom living without, and that we must nonetheless avoid catastrophic climate change if we are to have a world we might live in at all, it is vital that we set a goal of a lowcarbon future for non-negotiable technologies and begin to construct a plan for achieving this goal. If we are serious about tackling 'wicked' sustainability problems like climate change we need to consider how we can support the nonnegotiable technology for the entire population the planet, and how we can support these non-negotiable technologies with low or even zero-carbon footprint. Could everyone live like Bettina, with growth happening less frequently?

\section{B. Becoming systems thinkers}

The sustainability dilemma has implications far beyond the energy consumption of technology, the homes we live in, and so forth. As we have attempted to demonstrate in this paper, the unsustainable growth and impacts of domestic digital technologies are part of a wider system of cultural norms (e.g. expectations of friends, family, and work) and various other forces (e.g. the economic imperative for more 'stuff'). We offered low impact ideas not purely for critiquewe would argue that attending to the things that we might reasonably assume to be 'our responsibility' as people with the know-how to realise these (albeit) small wins is necessary but insufficient. We clearly must improve in terms of recognising and designing with an awareness of the systems-level impacts of our research and development. And yet, for many of us in this field, systems thinking is foreign and difficult (c.f. [37]). Perhaps this is because digital technologies have obvious potential to reduce energy and emissions impacts in some areas of practice (e.g. video conferencing vs. travel), but difficulty in accounting for other impacts and outputs [3] (e.g. videoon-demand doesn't only replace the physical media, it can also encourage additional demand). But how can we improve? Answering that question may be the key to unlocking many more radical directions for limiting growth in use, interactions, and non-use of digital technologies.

\section{Conclusion}

From our participants we have captured variation in daily practices that involve digital technology. Although our set of participants may not necessarily be representative of less technologically dependant populations, we are confident that 
they sufficiently represent how digital technology is impacting everyday life and leading to growing usage and interactions, and increasing (energy, data) impacts and demand.

Digital technology has both positive and negative social impacts (e.g. allowing Xander to 'hang out' with his brother, enabling Glenda to do her work whilst in France) with varying environmental impacts (e.g. instant messaging on a smart phone vs. large desktop PCs and cloud services for socialising whilst gaming). These practices achieve similar goals but have vastly different impacts and meanings.

We suggest that if research disciplines (ICT4S, HCI, Ubicomp) are to successfully progress towards a more sustainable future they must begin to consider limits to growth and more regularly attempt at more radical, more impactful changes (e.g. designing for non-reliance, a zero carbon future for nonnegotiable), instead of putting the majority of its efforts into low(er) impact persuasion (e.g. attending to the impacts of background tasks).

\section{ACKNOWLEDGMENT}

This work was funded by the UK Research Councils (refs. EP/G008523/1 \& EP/I00033X/1). This work was partially supported by a PhD CASE studentship from the EPSRC and Microsoft Research. We would like to thank Energy Lancaster for their ongoing support and cooperation. Finally, we would like to thank our reviewers for their insightful feedback, affording us the opportunity to improve this work for publication. In accordance to the research protocol signed by our participants, and to protect them from re-identification, the interview transcripts and photographs are not being made openly available in our institutional archive.

\section{REFERENCES}

[1] C. Lord, M. Hazas, A. K. Clear, O. Bates, J. Morley, and A. Friday, "Demand in my pocket: mobile devices and the data connectivity marshalled in support of everyday practice," in Proc. CHI, 2015.

[2] S. Turkle, Alone together: Why we expect more from technology and less from each other. Basic books, 2012.

[3] D. Pargman and B. Raghavan, "Rethinking sustainability in computing: From buzzword to non-negotiable limits," in Proc. of NordiCHI, 2014.

[4] I. Røpke and T. H. Christensen, "Energy impacts of ICT - insights from an everyday life perspective," Telematics and Informatics, 2012.

[5] M. Börjesson Rivera, C. Håkansson, Å. Svenfelt, and G. Finnveden, "Including second order effects in environmental assessments of ict," Environmental Modelling \& Software, vol. 56, pp. 105-115, 62014.

[6] E. Shove, M. Pantzar, and M. Watson, The Dynamics of Social Practice: Everyday life and how it changes. Sage, 2012.

[7] O. Bates, M. Hazas, A. Friday, J. Morley, and A. K. Clear, "Towards an holistic view of the energy and environmental impacts of domestic media and it," in Proc. CHI, 2014.

[8] A. Crabtree, R. Mortier, T. Rodden, and P. Tolmie, "Unremarkable networking: The home network as a part of everyday life," in Proc. DIS, 2012.

[9] E. M. Huang and K. N. Truong, "Breaking the disposable technology paradigm: opportunities for sustainable interaction design for mobile phones," in Proc. CHI, 2008.

[10] W. Odom, J. Pierce, E. Stolterman, and E. Blevis, "Understanding why we preserve some things and discard others in the context of interaction design," in Proc. of CHI, 2009.

[11] S. Gegenbauer and E. M. Huang, "Inspiring the design of longer-lived electronics through an understanding of personal attachment," in Proc. DIS, 2012.
[12] — - "ipods, ataris, and polaroids: A personal inventories study of outof-use electronics in swiss households," in Proc. UbiComp, 2012

[13] W. Odom, J. Zimmerman, J. Forlizzi, A. López Higuera, M. Marchitto, J. Cañas, Y.-k. Lim, T.-J. Nam, M.-H. Lee, Y. Lee, D.-j. Kim, Y.-k. Row, J. Seok, B. Sohn, and H. Moore, "Fragmentation and transition: Understanding perceptions of virtual possessions among young adults in spain, south korea and the united states," in Proc. CHI, 2013.

[14] A. Woodruff, J. Hasbrouck, and S. Augustin, "A bright green perspective on sustainable choices," in Proc. CHI, 2008, pp. 313-322. [Online]. Available: http://doi.acm.org/10.1145/1357054.1357109

[15] K. Hanks, W. Odom, D. Roedl, and E. Blevis, "Sustainable millennials: attitudes towards sustainability and the material effects of interactive technologies," in Proc. CHI, 2008. [Online]. Available: http://doi.acm.org/10.1145/1357054.1357111

[16] D. Prunel, E. L. Perasso, A. Roy, and C. Moulin, "Environmental labelling of mobile phones : Lca standardisation process," in ICT4S14, 2014.

[17] C. Remy and E. M. Huang, "Addressing the obsolescence of end-user devices: Approaches from the field of sustainable hci," in ICT4S-14, 2014.

[18] M. Håkansson and P. Sengers, "No easy compromise: Sustainability and the dilemmas and dynamics of change," in Proc. DIS, 2014.

[19] — "Beyond being green: simple living families and ict," in Proc. CHI, 2013.

[20] F. Kawsar and A. B. Brush, "Home computing unplugged: why, where and when people use different connected devices at home," in Proc. UbiComp, 2013.

[21] H. Jung, E. Stolterman, W. Ryan, T. Thompson, and M. Siegel, "Toward a framework for ecologies of artifacts: How are digital artifacts interconnected within a personal life?" in Proc. of NordiCHI, 2008.

[22] R. Silverstone and E. Hirsch, Consuming technologies: Media and information in domestic spaces. Psychology Press, 1992.

[23] A. K. Clear, M. Hazas, J. Morley, A. Friday, and O. Bates, "Domestic food and sustainable design: A study of university student cooking and its impacts," in Proc. CHI, 2013.

[24] L. M. Hilty, Information technology and sustainability: Essays on the relationship between information technology and sustainable development. BoD-Books on Demand, 2011.

[25] T. Quandt and T. v. Pape, "Living in the mediatope: A multimethod study on the evolution of media technologies in the domestic environment," The Information Society, vol. 26, no. 5, pp. 330-345, 2015/03/28 2010.

[26] D. Southerton, "'squeezing time': Allocating practices, coordinating networks and scheduling society," Time \& Society, 2003.

[27] Y. S. Lee, T. L. Smith-Jackson, and G. H. Kwon, "Domestication of technology theory: Conceptual framework of user experience," in Adjuct proc CHI, 2009.

[28] C. Preist and P. Shabajee, "Energy use in the media cloud: Behaviour change, or technofix?" in Proc. CloudCom, Nov 2010.

[29] B. Knowles, L. Blair, M. Hazas, and S. Walker, "Exploring sustainability research in computing: Where we are and where we go next," in Proc. UbiComp, 2013.

[30] M. S. Silberman, L. Nathan, B. Knowles, R. Bendor, M. Håkansson, T. Dillahunt, and J. Mankoff, "Next steps for sustainable hci," interactions, 2014.

[31] B. Tomlinson, M. S. Silberman, D. Patterson, Y. Pan, and E. Blevis, "Collapse informatics: augmenting the sustainability \& ICT4D discourse in HCI," in Proc. CHI, 2012.

[32] J. C. Mankoff, E. Blevis, A. Borning, B. Friedman, S. R. Fussell, J. Hasbrouck, A. Woodruff, and P. Sengers, "Environmental sustainability and interaction," in Proc. CHI EA, 2007.

[33] C. DiSalvo, P. Sengers, and H. Brynjarsdóttir, "Mapping the landscape of sustainable hci," in Proceedings of the SIGCHI Conference on Human Factors in Computing Systems, 2010.

[34] E. Blevis, "Sustainable interaction design: invention \& disposal, renewal \& reuse," in Proc. of CHI, 2007.

[35] A. J. B. Brush and K. M. Inkpen, "Yours, mine and ours? sharing and use of technology in domestic environments," in Proc. of UbiComp, 2007.

[36] S. E. Lindley, "Making time," in Proc. CSCW, 2015.

[37] S. Easterbrook, "From computational thinking to systems thinking: A conceptual toolkit for sustainability computing," in ICT4S-14, 2014. 